\title{
Multienvironment Evaluation of Tannin-Free Photoperiod-Insensitive Sorghum (Sorghum bicolor (L) Moench) for Yield and Resistance to Grain Mold in Senegal
}

\author{
Cyril Diatta ${ }^{D},{ }^{1,2,3}$ Mame P. Sarr ${ }^{D}{ }^{2}$, Thierry Klanvi Tovignan $\left(\mathbb{D},{ }^{1,4,3}\right.$ Ousmane Aidara $(\mathbb{D})^{2}$ \\ Daniel Kwadjo Dzidzienyo $\mathbb{D}^{3},{ }^{3}$ Elisabeth Diatta-Holgate, ${ }^{1}$ Jacques Martin Faye $\mathbb{D}^{5}{ }^{\mathbf{5}}$ \\ Eric Yirenkyi Danquah $\mathbb{D},{ }^{3}$ Samuel Kwame Offei $\mathbb{D}^{3},{ }^{3}$ and Ndiaga Cisse $\mathbb{D}^{1}$ \\ ${ }^{1}$ Institut Sénégalais de Recherches Agricoles (ISRA), \\ Sénégal / Centre d'Etude Régional pour l'Amélioration de l'Adaptation à la Sécheresse (CERAAS) de Thiès, BP 3320, \\ Thiès Escales, Senegal \\ ${ }^{2}$ Institut Sénégalais de Recherches Agricoles (ISRA), Sénégal / Centre National de Recherches Agronomiques (CNRA) de Bambey, \\ BP 53, Bambey, Senegal \\ ${ }^{3}$ West Africa Centre for Crop Improvement, University of Ghana, PMB LG 30 Legon, Accra, Ghana \\ ${ }^{4}$ Département de Génétique et Biotechnologie, Faculté des Sciences et Techniques (FAST), Université d'Abomey-Calavi (UAC), \\ BP 1947, Cotonou, Benin \\ ${ }^{5}$ Department of Agronomy, Kansas State University, New York, NY 66506, USA
}

Correspondence should be addressed to Cyril Diatta; batacyril@yahoo.fr

Received 14 January 2021; Accepted 7 May 2021; Published 20 May 2021

Academic Editor: Daryl Bowman

Copyright (c) 2021 Cyril Diatta et al. This is an open access article distributed under the Creative Commons Attribution License, which permits unrestricted use, distribution, and reproduction in any medium, provided the original work is properly cited.

\begin{abstract}
Combining resistance to grain mold with high grain yield in tannin-free white-grained photoperiod-insensitive sorghum is of major interest for farmers in Senegal. In this study, GGE biplot analysis was used to assess the performance, adaptability, and stability of eleven sorghum parental lines and their hybrid combinations for yield and grain mold resistance under Senegalese environments. Eleven inbred lines along with their 22 hybrid combinations and one check were evaluated across three sites during the 2015 and 2016 rainy seasons under natural grain mold infestation. The results of this study showed strong genetic variability among studied genotypes for all measured traits. The highly significant $G \times E$ interaction effects for grain yield and panicle grain mold rating score (PGMR) indicated that both traits are influenced by genetics and to some extent by environment. Broad-sense heritability computed was high for all these traits except PGMR, showing a high environmental pressure on this later. The study showed that grain mold pressure in the studied sites decreased following a South-North gradient similar to the rainfall pattern, with the south region wetter, explaining the high disease pressure in Darou and Sinthiou Maleme contrary to Bambey. The GGE biplot analysis performed showed that the first two principal components explained $85.84 \%$ of the total variation of GGE sum of squares for grain yield. The whichwon-where view of the GGE biplot for grain yield showed that the hybrid HB16 was the most adapted for Bambey area. The ranking of genotypes based on both yield performance and stability showed that HB16, HB5, HB21, HB18, and HB7 were the best hybrids combining high grain yield, high stability performance, and tolerance to grain mold disease across the test environments. These hybrids outperformed the best yielding inbred line P29 $\left(2196.7 \mathrm{~kg} \mathrm{ha}^{-1}\right)$ with grain yield advantages ranging $17-60 \%$. Therefore, these hybrids could be recommended to farmers in order to improve sorghum yield in Senegal.
\end{abstract}

\section{Introduction}

Sorghum is an important cereal crop extensively grown in Senegal during the rainy season and along the Senegal River
Valley during the water flooding recession. In 2017, sorghum production in Senegal averaged 225,865 tons under a cultivated area of $221,329 \mathrm{ha}$ [1]. The major growing regions in the country are Kaffrine, Tambacounda, and Kolda that 
account for about $62.8 \%$ of the national sorghum production [1]. Sorghum has good adaptation to a wide range of ecological conditions, requires low inputs for cultivation, and amenable for various end uses [2]. In Senegal, sorghum is mainly used as food, feed, fodder, and more recently involved in food processing activities such as bread making [3]. Moreover, sorghum grain is an important source of energy, protein, vitamins, and minerals for many households [4]. However, the yield of sorghum in the farmer's field is very low $\left(1020 \mathrm{kgha}^{-1}\right)$ and far below the needs of the population [1].

To reduce the yield gaps and to increase sorghum production, breeding for high yielding hybrids is known to be more productive than relying on landraces and purlines [5-7]. In Senegal, efforts have been made by the national sorghum breeding program to develop high yielding, tannin-free, photoperiod-insensitive cultivars belonging to the race caudatum. These efforts have led to the release of several tannin-free semicompact varieties such as CE151-262, CE196-7-2, 93B1057, F2-20, Nguinthe, Faourou, Nganda, and Darou whose yield is between 2 and $3 \mathrm{tha}^{-1}$ in farmer's field and are highly appreciated for their grain quality [8]. However, as these varieties were bred for earliness, in prolonged growing season, they mature before the end of the rainy season and are readily infected by grain mold that results in poor nutritional quality of the grain and poor germination rate when the contamination is high [9].

In Senegal, grain mold disease is one of the main constraints to the adoption of improved short- and mediumduration tannin-free photoinsensitive sorghum varieties $[10,11]$. The occurrence of the disease depends on the growing region, years, cultivars, and the prevailing weather conditions during the grain filling phase. Grain mold of sorghum is caused by a complex of more than 40 genera of pathogenic and saprophytic fungi $[12,13]$. The most important genera infecting sorghum grain in Senegal are Fusarium, Curvularia, Helminthosporium, Alternaria, and Phoma, with Fusarium verticillioides and Curvularia lunata being more virulent $[11,14,15]$. These species, individually or in combination affect sorghum grain quality resulting in significant yield losses $[16,17]$. The estimated field production losses due to grain mold ranges from $30 \%$ to $100 \%$ [18]. This results in a reduction in food availability, exposure to health risks through contaminated food, and income losses through lower prices [19]. Efforts in improving grain mold resistance in high yielding genotypes have been limited because the disease is governed by multiple mechanisms of resistance. Previous studies indicated that grain mold resistance in sorghum is governed by several major and minor genes that are influenced by genotype $(G)$, environment $(E)$, and $G \times E$ interactions $[9,16,20,21]$. In this context, multienvironment trials (MET) are important for studying yield stability and adaptation, as well as for the prediction of yield performance of genotypes across environments [22].

The GGE biplot model has been considered as an effective method to identify genotype differences under several testing environments [23]. This methodology is composed of two concepts, the biplot concept [24] and GGE concept [25]. It is now widely used by crop breeders in MET analysis for estimating mean performance, stability of cultivars, and discrimination of test sites [26, 27]. GGE biplot methods are graphical procedures that are able to interpret the $G \times E$ interaction in the site regression model [28]. This model assumes that the main effect of the environment is not relevant in the selection of genotype $(G)$, with the $G$ effect presented as a multiplicative $G \times E$ effect [29]. The popularity of the GGE biplot methodology is due to its flexibility and ability to analyze a range of data types with a two-way structure. It has been used in sorghum to investigate the $G \times E$ interaction for several traits such as yield, drought tolerance, stem sugar, grain iron, and zinc concentration [7, 29-31]. In a recent study, high yielding sorghum hybrids (AVG- $1 \times$ Nganda and AVG- $1 \times$ Darou) have been identified as the most stable and tolerant to grain mold infestation, suitable for the center and southeast regions of Senegal [8]. The present study was conducted to identify the suitable material for this zone and increase yield in farmers' fields in terms of improved varieties. The current study was conducted to (i) identify the best hybrids and parents having both high grain yield and resistance to grain mold, (ii) estimate the stability of the response of hybrids and parents to grain mold and grain yield, and (iii) identify genotypes with a broad or specific adaptation to the tested sites.

\section{Materials and Methods}

2.1. Plant Materials and Testing Sites. The $22 \mathrm{~F}_{1}$ hybrids of the present investigation were obtained from the crosses between each of the 11 white-grained tannin-free photoinsensitive lines Darou, Dorado, 93B1057, F2-20, Faourou, Macia, Nganda, Nguinthe, Sureño, CE151-262, CE196-7-2 used as male parents, with each of the two cytoplasmic male sterile (CMS) female parents CE310-31A and AVG-1, according to the line $\times$ tester mating design developed by Kempthorne [32]. The $22 \mathrm{~F}_{1}$ hybrids, their 13 parental lines (11 male lines and 2 female B-lines), and one grain mold tolerant hybrid check $(\mathrm{CE} 310-31 \mathrm{~A} \times 75-1)$ were evaluated during the rainy seasons in 2015 and 2016 under natural grain mold infestation at Bambey, Darou-Pakathiar, and Sinthiou Maleme research stations as shown in Figure 1.

In these three locations, the trials were laid out in a sandy-clay soil characterized by sand (86-90\%), silt loam (2-5\%), and clay (6-10\%) [33]. The climatic conditions during the two years of evaluation are given in Table 1.

2.2. Experimental Design and Field Management. The 36 sorghum genotypes were arranged in a $6 \times 6$ lattice design with three replications at each location. Each plot comprised of two rows of $5.2 \mathrm{~m}$ length with interrow spacing of $80 \mathrm{~cm}$ and intrarow spacing of $40 \mathrm{~cm}$. Fifteen days after planting, all rows were thinned to three plants per hill giving a population density of about 87740 plants per hectare. Standard cultural practices recommended for sorghum production were adopted across all locations. Before planting, NPK fertilizer (15-15-15) was applied as a basal dose at the rate of $150 \mathrm{~kg} \mathrm{ha}^{-1}$. Urea was applied at the rate of $100 \mathrm{~kg} \mathrm{ha}^{-1}$, in two split doses of $50 \mathrm{~kg} \mathrm{ha}^{-1}$, the first after thinning and the next at the booting stage. 


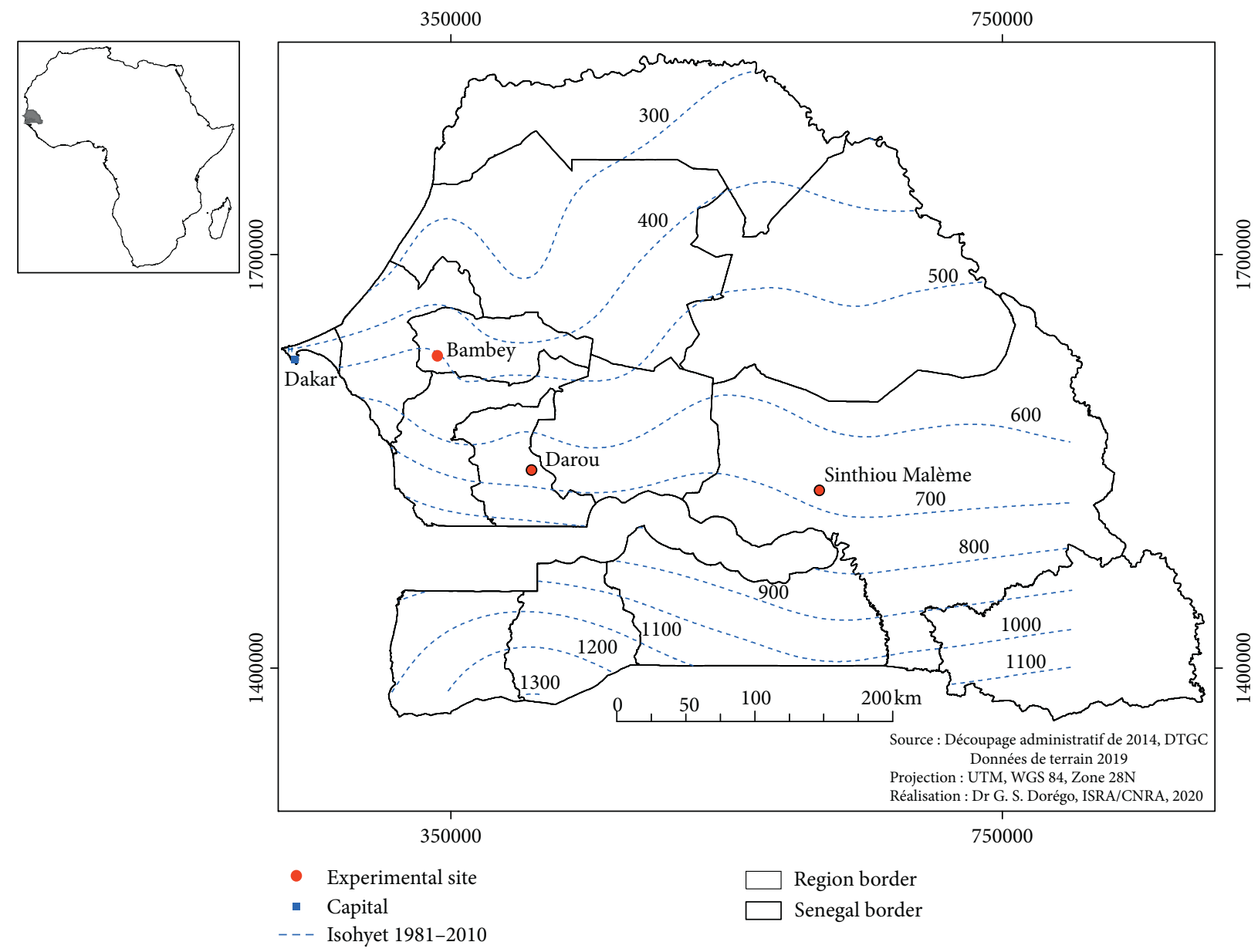

FIgURE 1: Map of Senegal showing the experimental locations, Darou=Darou-Pakathiar.

TABle 1: Precipitation, temperature, and relative humidity for Bambey, Darou, and Sinthiou Maleme during the growing seasons between July and October in 2015 and 2016.

\begin{tabular}{|c|c|c|c|c|c|c|c|c|c|}
\hline \multirow{2}{*}{ Location } & \multicolumn{3}{|c|}{ Precipitation } & \multicolumn{3}{|c|}{ Temperature $\left({ }^{\circ} \mathrm{C}\right)$} & \multicolumn{3}{|c|}{ Relative humidity (\%) } \\
\hline & Year & $\mathrm{mm}$ & Days & Min. & Max. & Mean & Min. & Max. & Mean \\
\hline \multirow{2}{*}{ Bambey } & 2015 & 689.4 & 35 & 24.3 & 34.4 & 29.3 & 54.8 & 97.7 & 76.0 \\
\hline & 2016 & 363.9 & 36 & 24.1 & 35.5 & 29.8 & 53.9 & 97.0 & 75.4 \\
\hline \multirow{2}{*}{ Darou } & 2015 & 685.3 & 46 & 22.2 & 33.4 & 27.8 & 59.7 & 95.0 & 77.0 \\
\hline & 2016 & 894.4 & 20 & 22.8 & 34.4 & 28.6 & 52.5 & 94.0 & 74.0 \\
\hline \multirow{2}{*}{ Sinthiou Maleme } & 2015 & 493.0 & 52 & 22.3 & 34.5 & 28.5 & 49.8 & 97.3 & 74.5 \\
\hline & 2016 & 525.5 & 43 & 22.5 & 35.3 & 28.9 & 47.9 & 94.0 & 73.5 \\
\hline
\end{tabular}

Min., minimum; Max., maximum; mm, millimeter; ${ }^{\circ} \mathrm{C}$, degree Celsius; \%, percentage.

2.3. Data Collection. At each location, climatic conditions such as temperature, relative humidity, and rainfall were recorded daily. Agromorphological parameters and observations recorded include number of days from planting to $50 \%$ flowering (TFlo), plant height $(\mathrm{PH})$ as the length of the plant from the soil to the tip of the panicle, panicle length (LPan), thousand-grain weight (TGW), grain yield (GYield), and panicle grain mold rating score (PGMR). Grain mold score was recorded at physiological maturity on panicles before harvesting, using the 1-5 scale as described by Thakur et al. [34], where $1=0$ to $<1 \%$ of mold visible on the panicle; $2=1-10 \%$ of the panicle surface covered by mold; $3=11-25 \%$ of the panicle surface molded; $4=26-50 \%$ of the panicle surface molded; and $5=$ mold infestation with more than $50 \%$ of the surface molded.

2.4. Statistical Analysis. Data of each location were first subjected to analysis of variance using the command PROC GLM procedure implemented in SAS 9.4 (SAS Institute Inc., 2013). Due to the homogeneity of error variance, the combined analysis across environments was performed using the following linear additive model: 


$$
Z_{\mathrm{ijklm}}=\mu+Y_{i}+S_{j}+\mathrm{YS}_{\mathrm{ij}}+R_{k}+B_{l}+G_{m}+B(\mathrm{YS})_{\mathrm{ijkl}}+(\mathrm{YG})_{\mathrm{im}}+(\mathrm{SG})_{\mathrm{jm}}+(\mathrm{YSG})_{\mathrm{ijk}}+\varepsilon_{\mathrm{ijk \textrm {ki }}}
$$

where $Z_{\mathrm{ijklm}}$ is the phenotypic observation of genotype $m$ in replicate $k$ of block $l$ of site $j$ and year $i$; $\mu$ is the grand mean; $Y_{i}$ is the effect of year $i, S_{j}$ is the effect of site $j ; R_{k}$ is the effect of replication in site $j$ and year $i ; G_{m}$ is the effect of genotype $m, B(\mathrm{YS})_{\mathrm{ijkl}}$ is the effect of block $l$ nested with replication $k$ in site $j$ and year $i$; (YS $)_{\mathrm{ij}}$ is the interaction between year $i$ and site $j ;(\mathrm{YG})_{\mathrm{im}}$ is the interaction between year $i$ and genotype $m$; $(\mathrm{SG})_{\mathrm{jk}}$ is the interaction between site $j$ and genotype $m$; (YSG) $)_{\mathrm{ijk}}$ is the interaction between year $i$, location $j$, and genotype $m$, and $\varepsilon_{\mathrm{ijklm}}$ is the residual effect.

Broad-sense heritability $\left(H^{2}\right)$ based on combined results across sites and years were estimated by the following formula:

$$
H^{2}=\frac{\sigma_{g}^{2}}{\left(\sigma_{g}^{2}+\sigma_{\mathrm{gs}}^{2} / s+\sigma_{\mathrm{gy}}^{2} / y+\sigma_{\mathrm{gsy}}^{2} / \mathrm{sy}+\sigma_{e}^{2} / \mathrm{rsy}\right)},
$$

where $\sigma_{g}^{2}$ is the genotypic variance; $\sigma_{\mathrm{gs}}^{2}$ is the variance of genotype $\times$ site interaction; $\sigma_{\mathrm{gy}}^{2}$ is the variance of genotype $\times$ year interaction; $\sigma_{\text {gsy }}^{2}$ is the variance of genotype $\times$ site $\times$ year interaction; $\sigma_{e}^{2}$ is the error variance; $r$ is the number of replicates; $y$ is the number of years; and $s$ is the number of sites.

The presence of significant $G \times E$ interactions $(P<0.001)$ for grain yield (GYield) and panicle grain mold rating score was further analyzed by testing for $G \times E$ components using the GGE biplot analysis. Each location-year combination was considered as an environment. The GGE biplot model was constructed using the formula suggested by Yan [28].

$$
Y_{\mathrm{ij}}-\bar{Y}_{j}=\lambda_{1} \varepsilon_{i 1} \eta_{j 1}+\lambda_{2} \varepsilon_{i 2} \eta_{j 2}+\varepsilon_{\mathrm{ij}}
$$

where $Y_{i j}$ is the mean performance of genotype $i$ in environment $j ; \bar{Y}_{j}$ is the overall mean yield over all genotypes in environment $j ; \lambda_{1}$ and $\lambda_{2}$ are the singular value of axis ${ }_{1}$ and axis $_{2}$, respectively; $\varepsilon_{i 1}$ and $\varepsilon_{i 2}$ are the axis ${ }_{1}$ and axis 2 scores, respectively, for genotype $i ; \eta_{j 1}$ and $\eta_{j 2}$ are the axis ${ }_{1}$ and axis 2 scores, respectively, for environment $j$; and $\varepsilon_{i j}$ is the residual of the model associated with genotype $i$ in environment $j$. The multienvironment data were analyzed based on a testercentered $(G+\mathrm{GE})$ without any scaling (scaling $=0)$. It is a row metric preserving GGE biplot, genotype focused, using singular value partitioning $(\mathrm{SVP}=1)$ for visualizing mean versus stability of genotypes. Environment-focused single value partitioning $(\mathrm{SVP}=2)$ was employed for location evaluation, and "which-won-where" option was used to identify which genotype was the winner in a given set of environments. GGE biplot analysis was performed using GGEBiplotGUI package [35] implemented in $R$ statistical software version 3.6.1 [36].

\section{Results}

3.1. Analysis of Variance and Descriptive Analysis. The combined analysis of variance (ANOVA) across sites and years showed that the mean squares for site, year, and site $\times$ year interaction were highly significant $(P<0.001)$ for all traits except for panicle length (Table 2). Genotype, genotype by year, and genotype by site interaction mean squares exhibited highly significant differences $(P<0.001)$ for all six measured traits across sites and years. Highly significant genotype $\times$ year $\times$ site interaction mean squares $(P<0.001)$ were also observed for grain yield (GYield), panicle grain mold rating score (PGMR), and all other measured traits.

3.2. Performance of Genotypes for the Six Measured Traits across the Tested Environments. Time from planting to flowering (TFlo) of parental lines and their hybrids varied from 61 days (HB1) to 78 days (P27) (Table 3). Hybrids were usually earlier than their parental lines. Among hybrids, the hybrids with the female parent CE310-31A were on average earlier than the ones with AVG-1 The average plant height of the genotypes was $202.2 \mathrm{~cm}$ with HB17 being the tallest hybrid combination $(281.7 \mathrm{~cm})$, and T36 (check), the shorter genotype $(151.3 \mathrm{~cm})$ followed by P30 and P27. Panicle length (LPan) ranged from $19.5 \mathrm{~cm}$ (P28) to $29.8 \mathrm{~cm}$ (HB12) with an average length of $26.3 \mathrm{~cm}$. The thousand-grain weight (TGW) varied from $13.3 \mathrm{~g}$ to $19.0 \mathrm{~g}$. The hybrid HB2 had the highest TGW, followed by HB5 and P24.

Hybrids were generally more productive than their parental lines. HB16 $\left(3,516.2 \mathrm{~kg} \mathrm{ha}^{-1}\right)$ recorded the highest grain yield followed by HB5 $\left(2,983.9 \mathrm{~kg} \mathrm{ha}^{-1}\right), \quad$ HB21 $\left(2,934.9 \mathrm{~kg} \mathrm{ha}^{-1}\right)$, HB18 $\left(2,855.0 \mathrm{~kg} \mathrm{ha}^{-1}\right)$, and HB7 $(2,822.3$ $\left.\mathrm{kg} \mathrm{ha}^{-1}\right)$. Among the hybrids, HB22 $\left(1,744.9 \mathrm{~kg} \mathrm{ha}^{-1}\right)$ was the poorest yielding hybrid with a yield slightly superior to that of the check T36 $\left(1,239.0 \mathrm{~kg} \mathrm{ha}^{-1}\right)$.

For the panicle grain mold rating score (PGMR), the parental line P27 was the most resistant genotype (2.4 score), followed by the hybrids HB16, HB22, HB21, and HB6 in that order with a PGMR score inferior or equal to 3 .

Broad-sense heritability was high for all six studied traits except for PGMR estimated at 0.26 (Table 3). PH was the most heritable trait (0.97), followed by TFlo (0.95). Heritability was also high for LPan (0.85), GYield (0.82), and thousand-grain weight $(0.77)$.

3.3. GGE Biplot Analysis. The GGE biplot analysis was carried out by considering high yielding genotypes with PGMR score between 1 and 3.4 (Table 3). Thus, 22 genotypes consisting of 15 hybrids, 6 parental inbred lines, and the check were subjected to the GGE biplot analysis for GYield and PGMR.

3.4. Mean Performance and Stability of Genotypes across Environments. Figure 2 shows the average-environment coordination (AEC) view of the GGE biplot. Together, axis 1 (69.39\%) and axis $_{2}$ (16.45\%) explained $85.84 \%$ of GGE sum of squares for grain yield. The single-arrowed line (AEC abscissa), which connects to the biplot origin, points to a 
TABLE 2: Mean squares ANOVA for six measured traits of sorghum parental lines and their hybrids evaluated at three sites in Senegal in 2015 and 2016.

\begin{tabular}{|c|c|c|c|c|c|c|c|}
\hline Source & Df & TFlo & $\mathrm{PH}$ & LPAN & TGW & GYield & PGMR \\
\hline Site & 2 & $5621^{* * *}$ & $76264^{* * *}$ & $611.6^{* * *}$ & $1050^{* * *}$ & $4603737^{* * *}$ & $48.19^{* * *}$ \\
\hline Year & 1 & $6026^{* * *}$ & $11213^{* * *}$ & $0.7^{\mathrm{ns}}$ & $120.2^{* * *}$ & $775988^{*}$ & $18.57^{* * *}$ \\
\hline Year (site) & 2 & $7255^{* * *}$ & $178788^{* * *}$ & $492.9^{* * *}$ & $1952.1^{* * *}$ & $78572254^{* * *}$ & $20.48^{* * *}$ \\
\hline Rep & 2 & $71^{* * *}$ & $3441^{* *}$ & $1.4^{\mathrm{ns}}$ & $6.4^{\mathrm{ns}}$ & $402340^{\mathrm{ns}}$ & $0.91^{* *}$ \\
\hline Block & 5 & $23^{*}$ & $1451^{\mathrm{ns}}$ & $6.2^{\mathrm{ns}}$ & $5.4^{\mathrm{ns}}$ & $48824^{\mathrm{ns}}$ & $0.26^{\mathrm{ns}}$ \\
\hline Block (site $\times$ year $)$ & 10 & $13^{\mathrm{ns}}$ & $1294^{*}$ & $4.3^{\mathrm{ns}}$ & $2.7^{\mathrm{ns}}$ & $252333^{\mathrm{ns}}$ & $0.17^{\mathrm{ns}}$ \\
\hline Genotype & 35 & $264^{* * *}$ & $20949^{* * *}$ & $118.4^{* * *}$ & $33.8^{* * *}$ & $5505741^{* * *}$ & $1.76^{* * *}$ \\
\hline Genotype $\times$ year & 35 & $17^{* * *}$ & $1304^{* * *}$ & $14.0^{* * *}$ & $11.5^{* * *}$ & $1085452^{* * *}$ & $1.41^{* * *}$ \\
\hline Genotype $\times$ site & 70 & $35^{* * *}$ & $1794^{* * *}$ & $15.0^{* * *}$ & $6.4^{* * *}$ & $828071^{* * *}$ & $0.46^{* * *}$ \\
\hline Genotype $\times$ year $\times$ site & 70 & $38^{* * *}$ & $2525^{* * *}$ & $11.3^{* * *}$ & $10.0^{* * *}$ & $922533^{* * *}$ & $0.56^{* * *}$ \\
\hline Residuals & 400 & 8 & 553 & 5.1 & 2.5 & 169149 & 0.16 \\
\hline
\end{tabular}

ns, $P>0.05 ;{ }^{*} P<0.05 ;{ }^{*} * P<0.01 ;{ }^{*} * *<0.001$; TFlo, time to 50\% flowering; PH, plant height; LPan, panicle length; TGW, thousand-grain weight; GYield, grain yield; PGMR, panicle grain mold rating score.

higher mean across environments for the trait analyzed $[35,37]$, which is here the grain yield. Thus, HB16 had the highest mean yield, followed by HB5, HB21, HB18, HB7, HB13, HB19, HB20, HB6, and HB11, whereas T36, P33, P27 P30, P23, HB22, HB14, P32, HB17, P25, and P22 recorded the lowest mean yield. The vertical axis (or AEC ordinate), which is perpendicular to the AEC abscissa and passes through the origin, represents the stability of genotypes in either direction. The shorter the absolute length of the projection of a genotype, the more stable it is [35]. Thus, HB19 was the most stable genotype for grain yield, followed by HB5, HB20, and HB18.

For panicle grain mold tolerance, Figure 3 shows the biplot presenting the mean performance and stability of genotypes across environments. As described for grain yield, the best performing genotype regarding grain mold tolerance was P27, followed by P29, HB16, HB6, HB21, P32, and HB17. Moreover, hybrid HB12 was the most stable, followed by HB16, HB20, and HB7. The parent P29 was the least stable for this trait.

3.5. Which-Won-Where Pattern Analysis. This approach locates the winning genotypes for each environment on the vertex of the polygon. The hybrids HB7, HB16, HB21, and HB13 were the winning genotypes for grain yield in the megaenvironment constituted by Bambey_2015, Darou_2015, Sinthiou_2015, and Bambey_2016 (Figure 4). During the rainy season of 2016, the parental line P29 was the vertex genotype at Darou, while no winning genotype was associated with Sinthiou_16. On the other hand, the hybrid HB12, parental line P23, and the check T36 were not associated with any of the test environments where the materials were evaluated.

The which-won-where pattern for grain mold tolerance is shown in Figure 5. The hybrid HB6 was the winning genotype for the megaenvironment constituted by Darou_16. The parental line P27 was the winning genotype for the megaenvironment constituted by Bambey_15, Bambey_16, Sinthiou_15, and Sinthiou_16. The parental line P29 was more associated with Darou_15. However, the genotypes HB5, HB7, and P33 were not associated with any tested environment.
3.6. Ranking Genotypes Relative to the Ideal Genotype. Ranking of the tolerant sorghum parental lines and hybrids for grain yield based on both mean and stability with regard to an "ideal" genotype is shown in Figure 6. The center of the concentric circle is where an "ideal" genotype should be. Its projection on the AEC $x$-axis was designed to be equal to the longest vector of all cultivars, and its projection on the AEC $y$-axis was obviously zero, meaning that it is absolutely stable $[28,35]$. An "ideal" genotype should have the highest mean performance and be absolutely stable [38]. Thus, genotype HB16 was the best performing and more stable genotype followed by HB18, HB5, HB7, and HB21 for grain yield across the tested environments. However, the check T36 was the least yielding and unstable genotype across environments.

As for panicle grain mold tolerance, the parent P27 was the best performing and stable genotype, followed by HB16, HB21, P32, HB6, HB17, and P29. Whereas the hybrid HB7 was the least performing and stable genotype (Figure 7).

\section{Discussion}

The combined analysis of variance showed that the genotype effect was highly significant $(P<0.001)$ for all measured traits, suggesting the presence of genetic variability among the parental lines and their hybrids for the six measured traits. The highly significant effect of $G \times E$ interaction observed for both grain yield and grain mold score, which indicates that effect of environment, significantly determined both grain yield and genotype response to grain mold. Significant $G \times E$ interaction in multienvironmental trials has been previously reported in sorghum for both grain yield $[29,31,39,40]$ and grain mold score $[9,16,20,21]$. Moreover, substantial differences in genotypic responses of the hybrids and their parental lines were observed between sites and between years on the same site. This differential response could be explained by differences in soil texture across sites [33], climatic conditions (temperature, relative humidity, and rainfall patterns) [19], and sucking insects [41], and the diversity of fungal species causing grain mold disease $[11,14,42,43]$. A report in Senegal about forty years ago reported the fungi Curvularia lunata and Fusarium spp 
TABLE 3: Mean per se performance of parental lines and their hybrids across the test environments.

\begin{tabular}{|c|c|c|c|c|c|c|c|}
\hline Genotypes & Code & TFlo & $\mathrm{PH}$ & LPan & TGW & GYield & PGMR \\
\hline CE 310-31 A ×93 B1057 & HB1 & 61.3 & 239.3 & 28.6 & 17.7 & 2167.3 & 3.5 \\
\hline CE $310-31 \mathrm{~A} \times \mathrm{CE} 151-262$ & HB2 & 62.6 & 189.9 & 29.0 & 19.0 & 2249.0 & 3.8 \\
\hline CE 310-31A $\times$ CE196-7-2 & HB3 & 65.1 & 253.3 & 25.7 & 15.6 & 2290.6 & 3.5 \\
\hline CE $310-31 \mathrm{~A} \times$ Darou & HB4 & 65.3 & 208.1 & 27.9 & 16.8 & 2370.6 & 3.5 \\
\hline CE 310-31A $\times$ Dorado & HB5 & 65.6 & 201.1 & 28.7 & 18.2 & 2983.9 & 3.3 \\
\hline CE $310-31 \mathrm{~A} \times \mathrm{F} 2-20$ & HB6 & 65.8 & 272.3 & 23.9 & 15.9 & 2414.7 & 3.0 \\
\hline CE 310-31A $\times$ Faourou & HB7 & 63.8 & 215.6 & 28.6 & 16.8 & 2822.3 & 3.4 \\
\hline CE $310-31 \mathrm{~A} \times$ Macia & HB8 & 63.1 & 204.8 & 28.6 & 17.1 & 2307.4 & 3.5 \\
\hline CE $310-31 \mathrm{~A} \times$ Nganda & HB9 & 64.6 & 208.1 & 28.9 & 16.7 & 2571.6 & 3.5 \\
\hline CE $310-31 \mathrm{~A} \times$ Nguinthe & HB10 & 64.2 & 221.5 & 28.8 & 17.2 & 2437.3 & 3.5 \\
\hline CE 310-31A × Sureño & HB11 & 68.8 & 235.8 & 25.5 & 16.5 & 2217.4 & 3.2 \\
\hline AVG-1 x 93B1057 & $\mathrm{HB} 12$ & 68.2 & 194.6 & 29.8 & 15.5 & 2143.4 & 3.4 \\
\hline AVG-1 x CE151-262 & HB13 & 65.3 & 188.3 & 28.9 & 16.3 & 2569.9 & 3.2 \\
\hline AVG-1 x CE196-7-2 & HB14 & 69.9 & 273.4 & 26.2 & 14.0 & 1917.9 & 3.3 \\
\hline AVG-1 x Darou & HB15 & 70.7 & 203.4 & 29.0 & 15.7 & 2683.4 & 3.5 \\
\hline AVG-1 x Dorado & HB16 & 69.0 & 203.4 & 27.8 & 17.1 & 3516.2 & 2.8 \\
\hline AVG-1 x F2-20 & HB17 & 70.7 & 281.7 & 23.7 & 14.7 & 1961.4 & 3.1 \\
\hline AVG-1 x Faourou & HB18 & 67.9 & 203.8 & 29.3 & 16.0 & 2855.0 & 3.2 \\
\hline AVG-1 x Macia & HB19 & 70.4 & 197.2 & 27.3 & 16.9 & 2456.0 & 3.2 \\
\hline AVG-1 x Nganda & HB20 & 68.6 & 203.6 & 28.7 & 14.5 & 2439.6 & 3.3 \\
\hline AVG-1 x Nguinthe & HB21 & 69.6 & 198.4 & 27.3 & 16.3 & 2934.9 & 3.0 \\
\hline AVG-1 x Sureño & HB22 & 70.6 & 243.8 & 24.1 & 13.4 & 1744.9 & 2.9 \\
\hline $93 \mathrm{~B} 1057$ & P23 & 67.4 & 182.1 & 27.1 & 16.4 & 1755.2 & 3.1 \\
\hline CE151-262 & $\mathrm{P} 24$ & 67.3 & 155.7 & 25.7 & 18.0 & 1975.7 & 3.6 \\
\hline CE196-7-2 & P25 & 69.2 & 199.7 & 21.2 & 14.5 & 1916.7 & 3.4 \\
\hline Darou & $\mathrm{P} 26$ & 71.8 & 194.8 & 26.5 & 15.7 & 2072.3 & 3.6 \\
\hline Dorado & $\mathrm{P} 27$ & 77.8 & 152.8 & 23.3 & 16.4 & 1726.7 & 2.4 \\
\hline $\mathrm{F} 2-20$ & P28 & 72.8 & 193.7 & 19.5 & 14.8 & 1522.9 & 3.6 \\
\hline Faourou & P29 & 72.8 & 171.9 & 23.8 & 16.0 & 2196.7 & 3.3 \\
\hline Macia & P30 & 72.4 & 152.7 & 23.5 & 15.1 & 1716.3 & 3.3 \\
\hline Nganda & P31 & 70.4 & 185.9 & 26.8 & 15.6 & 1608.6 & 3.7 \\
\hline Nguinthe & P32 & 70.5 & 170.2 & 24.9 & 15.6 & 1952.7 & 3.3 \\
\hline Sureño & P33 & 74.4 & 213.6 & 22.4 & 13.4 & 1605.0 & 3.0 \\
\hline CE 310-31B & P34 & 62.7 & 154.8 & 23.7 & 14.6 & 740.1 & 4.2 \\
\hline BVG-1 & P35 & 71.9 & 160.5 & 25.8 & 13.3 & 1259.9 & 3.7 \\
\hline $\mathrm{CE} 310-31 \mathrm{~A} \times 75-1$ & $\mathrm{~T} 36$ & 73.8 & 151.3 & 26.5 & 14.7 & 1239.0 & 3.4 \\
\hline Mean & & 68.5 & 202.2 & 26.3 & 15.9 & 2148.4 & 3.3 \\
\hline Min. & & 61.3 & 151.3 & 19.5 & 13.3 & 740.1 & 2.4 \\
\hline Max. & & 77.8 & 281.7 & 29.8 & 19.0 & 3516.0 & 4.2 \\
\hline CV (\%) & & 4.1 & 11.6 & 8.6 & 10.0 & 19.1 & 11.9 \\
\hline HSD & & 3.6 & 30.3 & 2.9 & 2.1 & 530.4 & 0.5 \\
\hline Heritability (broad sense) & & 0.95 & 0.97 & 0.85 & 0.77 & 0.82 & 0.26 \\
\hline
\end{tabular}

TFlo, time to 50\% flowering; PH, plant height; LPan, panicle length; TGW, thousand-grain weight; GYield, grain yield; PGMR, panicle grain mold rating score; Min., minimum; Max., maximum; CV, coefficient of variation; HSD, honest significant difference.

(F. moniliforme, F. equiseti, F. longipes, F. flocciferum, and F. sporotrichioides) being most frequently observed [14]. The high temperature $\left(33.4-35.5^{\circ} \mathrm{C}\right)$ and humidity $(94.0-97.7 \%)$ that prevailed during the growing season in the study areas in Senegal explain the rapid proliferation of the fungi. This also corroborates with the report of Tonapi et al. [19] in India, which reports a significant increase of fungal sporulation and grain mold severity with increasing incubation temperature $\left(25-28^{\circ} \mathrm{C}\right)$ and relative humidity (95-98\%). Moreover, the rainfall at Bambey decreased by $50 \%$ in 2016 compared to 2015, while at Darou, it increased by $209 \mathrm{~mm}$. At Sinthiou, it increased slightly by $32 \mathrm{~mm}$. In parallel, the degree of panicle infestation decreased slightly in Bambey by $6 \%$, increased by $10 \%$ in Darou, and decreased by $25 \%$ in
Sinthiou Maleme. The decrease of the rate of mold infestation in Sinthiou Maleme could be due to the reduction in the relative humidity, since the mold infestation is controlled by the set made up of hygrometry, temperature, and rainfall. Otherwise, our previous study reported that the grain mold pressure in the studied sites decreased following a SouthNorth gradient, with Sinthiou Maleme having the highest pressure and Bambey the lowest pressure [44]. The high influence of environments on the expression of grain mold reduces the accuracy for estimating disease resistance and selecting the appropriate germplasm [21].

Furthermore, this study showed that the broad-sense heritability estimates for agronomic traits such as time to $50 \%$ flowering, plant height, panicle length, thousand-grain 


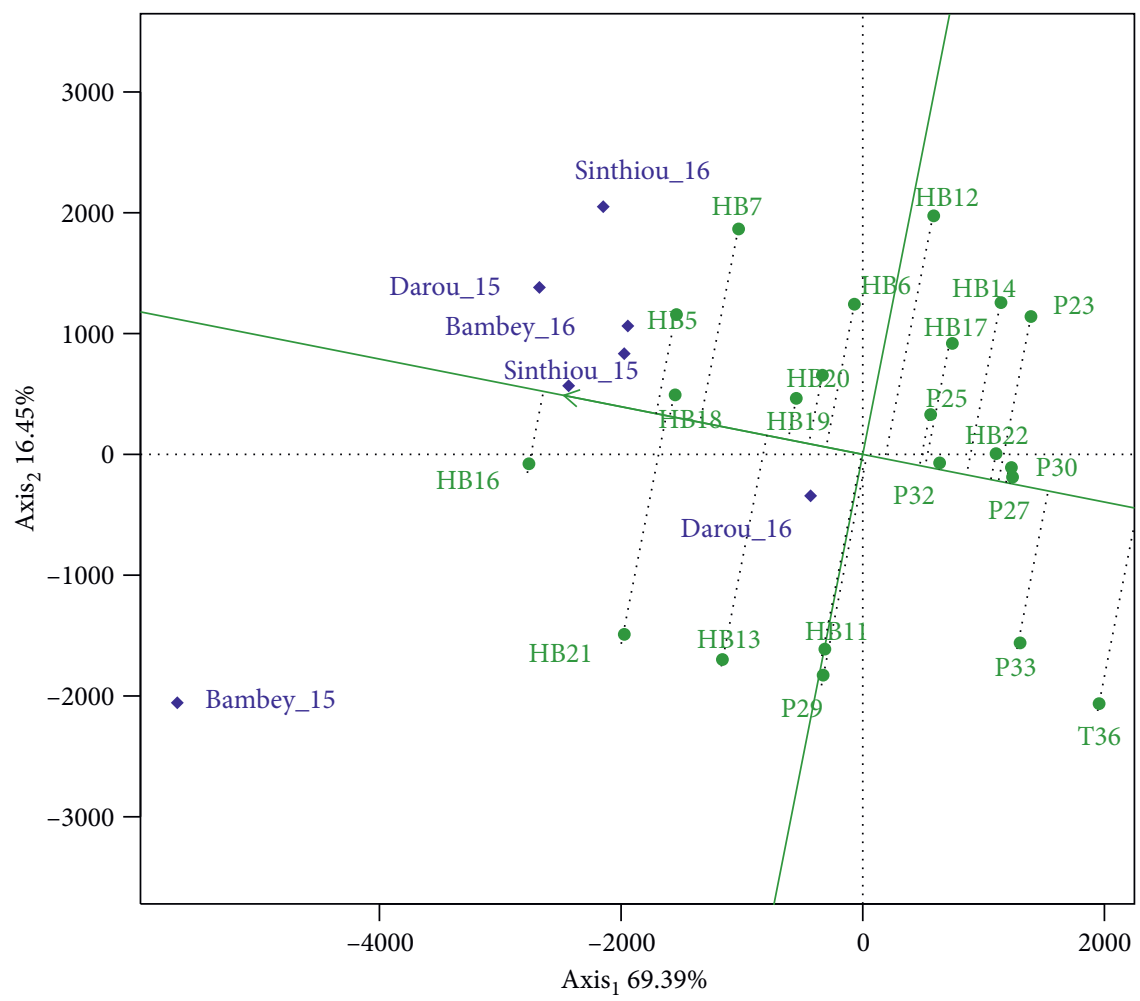

Figure 2: Average-environment coordination (AEC) view of sorghum hybrids and their parents for mean grain yield performance and stability based on GGE biplot analysis. The green single-arrowed horizontal line represents the AEC abscissa, and the green vertical line represents the AEC ordinate. The direction of AEC abscissa arrowhead indicates higher yield. The vertical projections on the AEC abscissa indicate stability of genotypes in either direction. Greater the projection, higher is the instability. Genotype and environment labels are represented in green and blue, respectively.

weight, and grain yield were high. This suggests that these traits were predominantly under genetic control, and their improvement can be realized through phenotypic selection. Similar results have been found by Phuke et al.[31]. However, in this study, the heritability estimate for panicle grain mold score (PGMR) at physiological maturity was low (0.26), as also observed by Audilakshmi et al. [16]. This denotes the strong influence of environment on the expression of this disease. However, a relatively high heritability estimate of $86 \%$ for grain mold has been reported by Rodríguez-Herrera et al. [21].

The parental lines P27 and P33 were identified as the most tolerant genotypes for grain mold disease. Although both varieties have the longest time to flowering, their resistance to grain mold disease has been previously reported by several studies carried out in Senegal and in other countries $[43,45]$. Worldwide, the popularity of P33 was due to its resistance to lodging, grain mold, and most of the major foliar diseases such as grey leaf spot (Cercospora sorghi), zonate leaf spot (Gloeocercospora sorghi), rust (Puccinia purpurea), leaf blight (Exserohilum turcicum), anthracnose (Colletotrichum sublineola), and downy mildew (Peronosclerospora sorghi) [45, 46]. Additionally, in a recent study, Diatta [44] reported that the variety P27 has a good general combining ability for grain yield and grain mold resistance. Therefore, these varieties could be used by breeders to improve the resistance of susceptible elite genotypes to grain mold disease. This study also identified HB16 and HB21 as the best hybrids combining both high grain yield and tolerance to grain mold disease. In addition to their free-tannin and white-grained status, these two hybrids outperformed the best yielding parental line P29 $\left(2,196.7 \mathrm{~kg} \mathrm{ha}^{-1}\right)$ with a yield advantages ranging $10-60 \%$ and confirmed the yield superiority of the hybrids over their parental lines $[6,7,47,48]$.

Which-won-where analysis identifies the best genotype for a given megaenvironment and allows the breeder to recommend genotypes for a particular environment [40]. A megaenvironment could be defined as a group of sites that consistently share the same best cultivar $(s)$ [49]. In this study, HB16 was identified as the most adapted hybrid combination for Bambey area. On the other hand, Darou_2015 and Darou_2016 as well as Sinthiou_2015 and Sinthiou_2016 environments did not fall into the same megaenvironment. This could probably be due to variability in weather conditions and rainy season patterns in these test sites from year to year. Such situations limit breeders' ability to recommend the most adapted cultivars to a given environment. Such situation demands increase in the number of years and sites of evaluation to ensure accurate decision making.

Furthermore, it can be said that one of the most exciting applications of GGE biplot methodology is the ranking of genotypes with reference to an "ideal" genotype. In this 


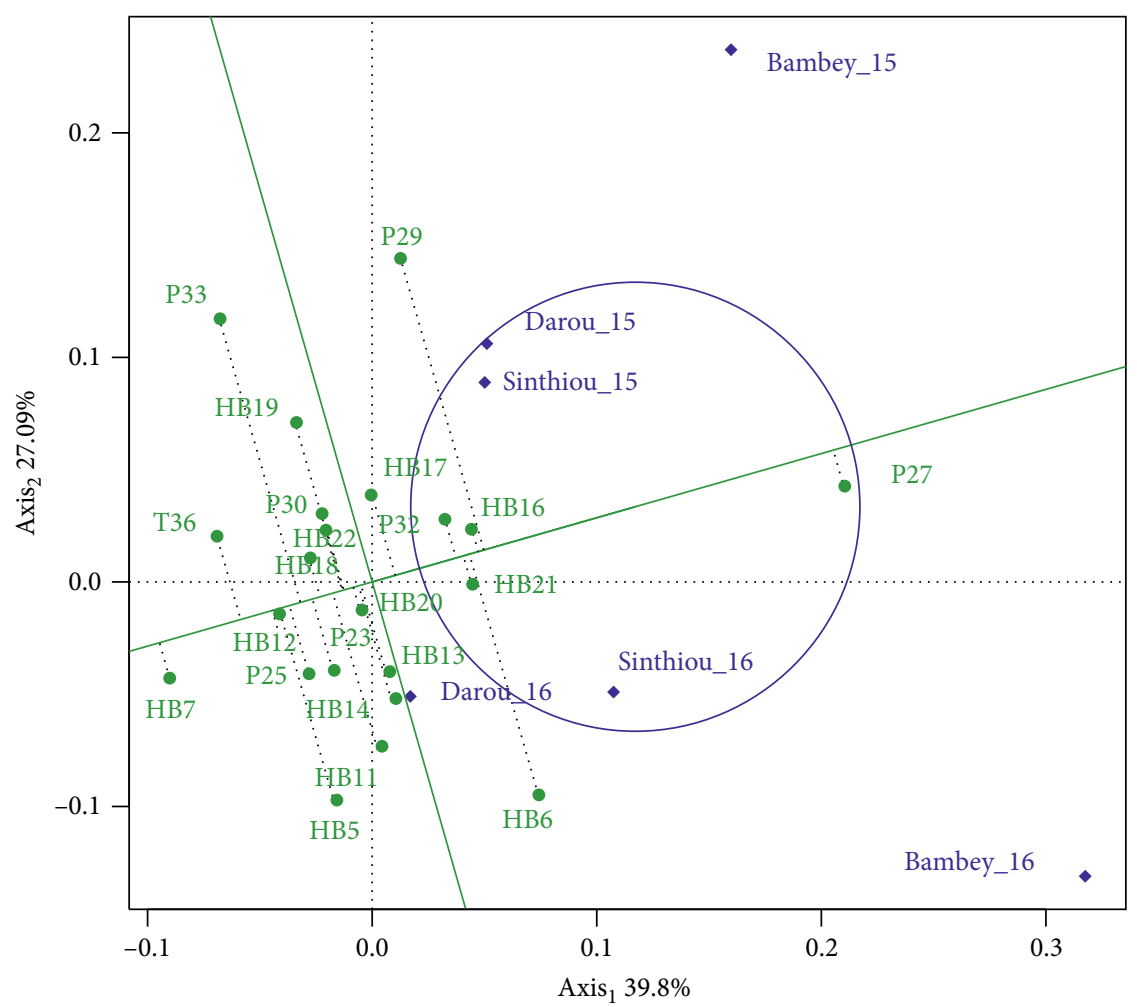

Figure 3: Average-environment coordination (AEC) view of sorghum hybrids and their parents for grain mold resistance performance and stability based on GGE biplot analysis. The green single-arrowed horizontal line represents the AEC abscissa, and the green vertical line represents the AEC ordinate. The direction of AEC abscissa arrowhead indicates higher yield. The vertical projections on the AEC abscissa indicate the stability of genotypes in either direction. Greater the projection, higher is the instability. Green and blue labels stand for genotypes and environments, respectively.

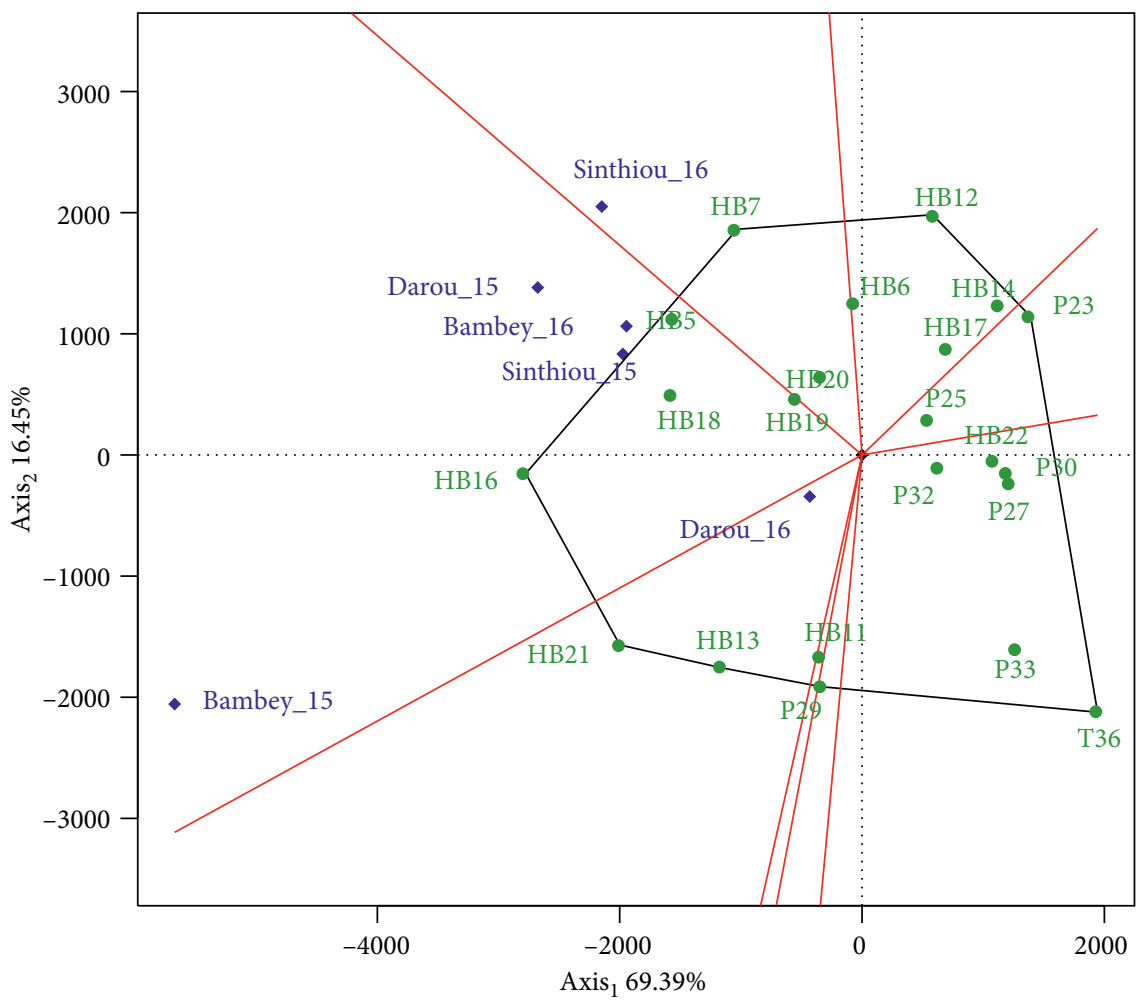

FiguRE 4: "Which-won-where" view of best grain mold resistant inbred lines and hybrid combinations based on grain yield. Red lines represent the megaenvironments; hybrids and inbred lines labels are written in green; locations labels are written in blue; dotted lines represent the axes. 


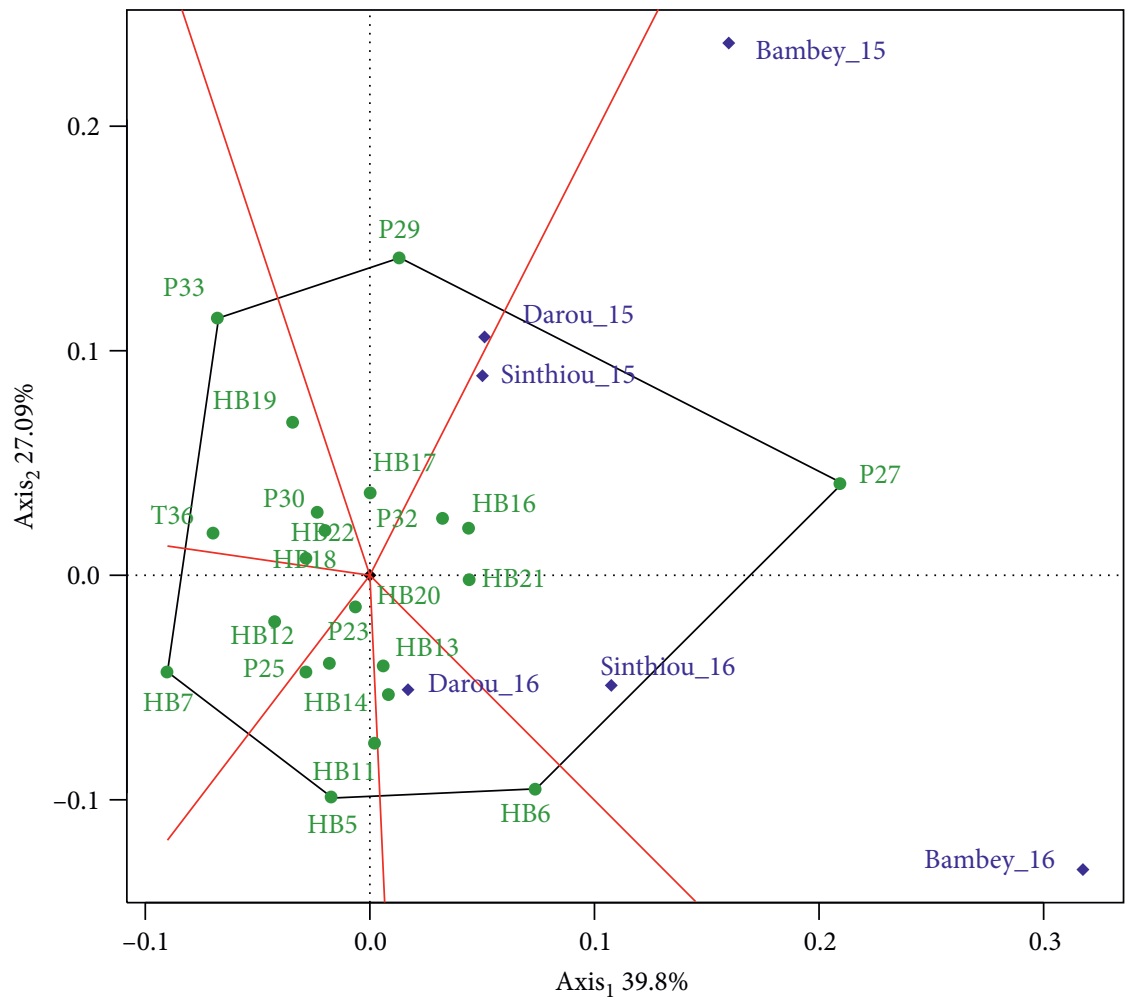

FiguRE 5: "Which-won-where" view of best grain mold tolerant inbred lines and hybrid combinations based on panicle grain mold resistance rating score. Red lines represent the megaenvironments; hybrids and inbred lines labels are written in green; locations labels are written in blue; dotted lines represent the axes.

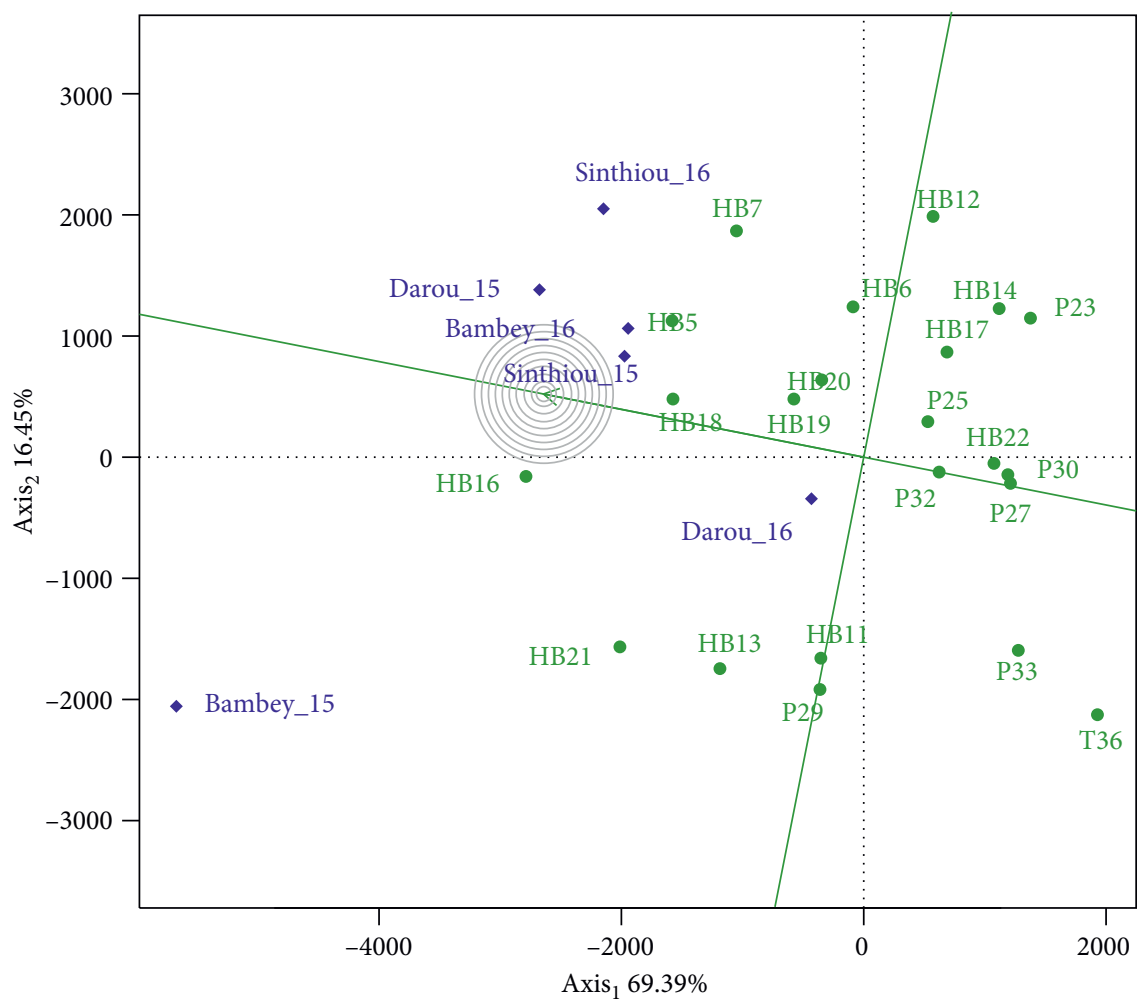

FIGURE 6: Ranking genotypes for grain yield based on both mean performance and stability with reference to an "ideal" genotype. The green single-arrowed horizontal line represents the AEC abscissa, and the green vertical line represents the AEC ordinate. The AEC abscissa arrowhead indicates where an "ideal" genotype should be. Its projection on the AEA was designed to be equal to the longest vector of all genotypes, and its projection on the AEC was obviously zero, meaning that it is absolutely stable. Genotypes located closer to the ideal genotype are more desirable than others. The concentric circles help to visualize the position of the genotype with respect to ideal genotype. Genotype and environment labels are represented in green and blue, respectively. 


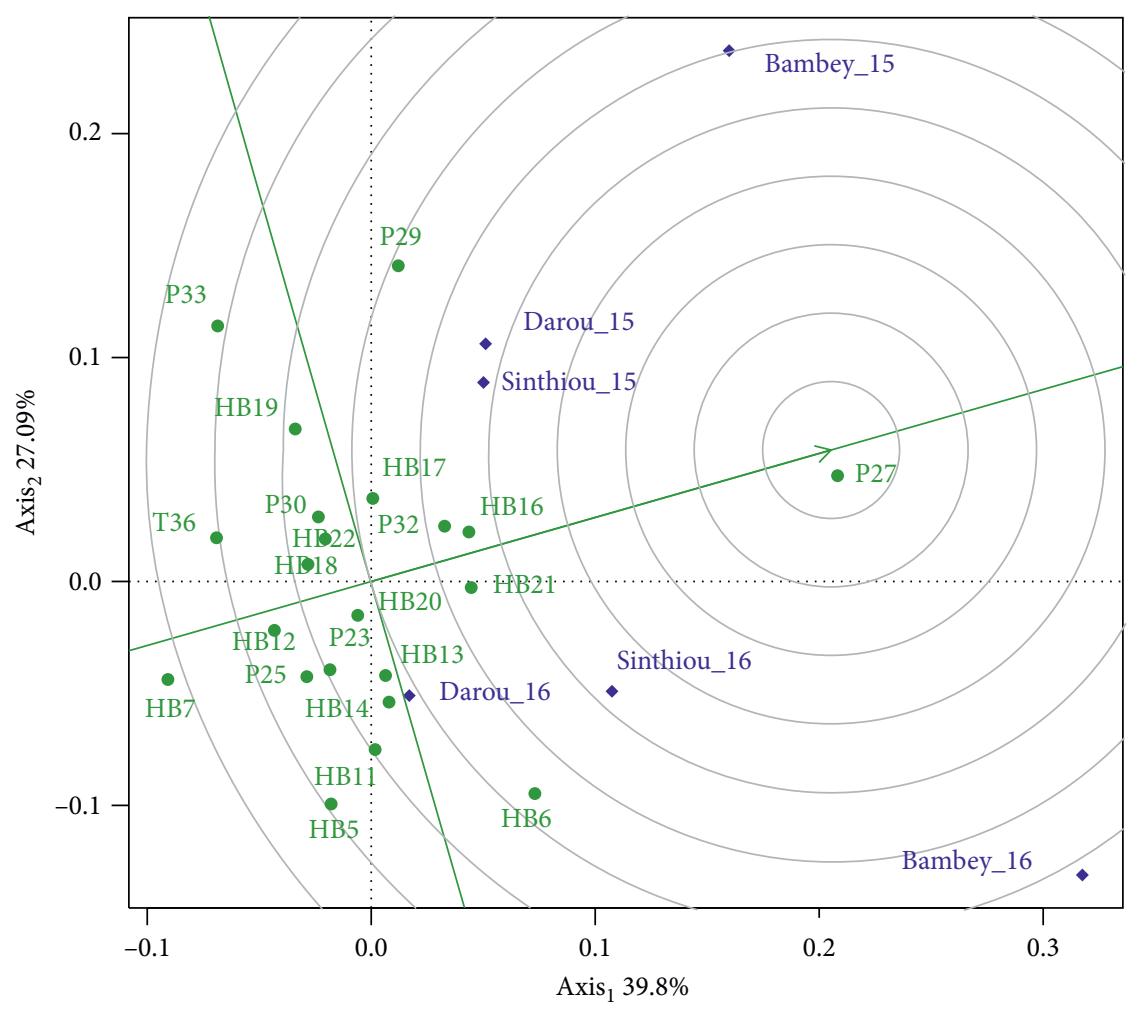

FIGURE 7: Ranking genotypes for grain mold resistance based on both mean performance and stability with reference to an "ideal" genotype. The green single-arrowed horizontal line represents the AEC abscissa, and the green vertical line represents the AEC ordinate. The AEC abscissa arrowhead indicates where an "ideal" genotype should be. Its projection on the AEA was designed to be equal to the longest vector of all genotypes, and its projection on the AEC was obviously zero, meaning that it is absolutely stable. Genotypes located closer to the ideal genotype are more desirable than others. The concentric circles help to visualize the position of the genotype with respect to ideal genotype. Genotype and environment labels are represented in green and blue, respectively.

study, the ranking of varieties with regard to the "ideal" genotype identified HB16, HB18, and HB5 as the best hybrids combining both mean performance and stability for grain yield. The stability and adaptability of varieties are important along with higher mean performance in determining the success of varieties [27]. In Senegal where the average sorghum grain yield in farmers' fields is still very low (around $1,000 \mathrm{~kg} \mathrm{ha}^{-1}$ ), the promotion of stable high yielding and grain mold tolerant hybrids will significantly contribute to increase in sorghum grain production per unit of area, increase the price, and therefore contribute to eradicate hunger from rural areas.

\section{Conclusion}

This study confirmed the resistant status of the varieties P27 and P33 to sorghum grain mold disease in Senegal. It identified the hybrids HB16 and HB21 as the best combinations for high grain yield performance, stability, and tolerance to grain mold disease. These hybrids outperformed the best yielding inbred line P29 with grain yield advantages ranging $10-60 \%$. For environment-specific adaptation, this study showed high intrasite variability in the response of hybrids at Darou and Sinthiou Maleme. The study identified promising hybrids that could positively boost sorghum production per unit of area in farmers' fields in Senegal.

\section{Data Availability}

The data used to support the findings of this study are available from the corresponding author upon request.

\section{Conflicts of Interest}

The authors declare that they have no conflicts of interest.

\section{Authors' Contributions}

$\mathrm{CD}, \mathrm{NC}, \mathrm{EYD}$, and SKO conceived and designed the study; $\mathrm{CD}, \mathrm{OA}$, and MPS performed the research; CD and TKT analyzed the data and wrote the manuscript; DKD, JMF, and $\mathrm{EDH}$ contributed to the results interpretation and provided a critical review on the final manuscript. All authors read and approved the final version of the manuscript.

\section{Acknowledgments}

The authors would like to thank Gualbert Seraphin Dorego, Gilles Trouche, and Mathieu Ayena for their helpful comments on the manuscript. The West Africa Agricultural Productivity Program (WAAPP, Senegal) partially funded this study and provided full scholarship to the first author. The authors also greatly appreciate the support of the American People provided to the Feed the Future 
Innovation Lab for Collaborative Research on Sorghum and Millet through the United States Agency for International Development (USAID).

\section{References}

[1] L. Shen, M. Ding, C. Feng, B. Yang, M. Elchalakani, and L. Song, "Experimental study on the cumulative damage constitutive model of high-performance steel Q345GJ under cyclic loading," Journal of Constructional Steel Research, vol. 181, 2018.

[2] C. Aruna, V. R. Bhagwat, V. Sharma et al., "Genotypexenvironment interactions for shoot fly resistance in sorghum (Sorghum bicolor (L.) Moench): response of recombinant inbred lines," Crop Protection, vol. 30, no. 6, pp. 623-630, 2011.

[3] M. Sambe, L. S. Tounkara, M. J. F. S. Lopy, and Y. N'Diaye, "Etude des comportements rhéologiques des mélanges de farine blé/sorgho sans tanins issue de trois nouvelles variétés cultivées au Sénégal et mise au point de pains à base de farines composées (blé/sorgho)," Journal of Agronomy, vol. 29, pp. 69-74, 2017.

[4] J. A. Winn, R. E. Mason, A. L. Robbins, W. L. Rooney, and D. B. Hays, "QTL mapping of a high protein digestibility trait in Sorghum bicolor," International Journal of Plant Genomics, vol. 2009, Article ID 471853, 6 pages, 2009.

[5] M. Kante, F. Rattunde, B. Nébié et al., "Sorghum hybrids for low-input farming systems in West Africa: quantitative-genetic parameters to guide hybrid breeding," Crop Science, vol. 59, 2019.

[6] I. Makanda, P. Tongoona, J. Derera, J. Sibiya, and P. Fato, "Combining ability and cultivar superiority of sorghum germplasm for grain yield across tropical low- and mid-altitude environments," Field Crops Research, vol. 116, no. 2, pp. 75-85, 2010.

[7] H. F. W. Rattunde, E. Weltzien, B. Diallo et al., "Yield of photoperiod-sensitive sorghum hybrids based on Guinea-race germplasm under farmers' field conditions in Mali," Crop Science, vol. 53, no. 6, pp. 2454-2461, 2013.

[8] C. Diatta, T. K. Tovignan, H. Adoukonou-Sagbadja et al., "Development of sorghum hybrids for stable yield and resistance to grain mold for the Center and South-East of Senegal," Crop Protection, vol. 119, pp. 197-207, 2019.

[9] S. S. Ambekar, M. Y. Kamatar, K. Ganesamurthy et al., "Genetic enhancement of Sorghum (Sorghum bicolor (L) Moench) for grain mould resistance: II. Breeding for grain mould resistance," Crop Protection, vol. 30, no. 7, pp. 759-764, 2011.

[10] C. Luce, "L’amélioration du sorgho au Sénégal : acquis (19501986) et perspectives de recherches," Institut Sénégalais de Recherches Agricoles (ISRA), vol. 1, no. 2, p. 22, 1988.

[11] D. Louvel, Phytopathologie du sorgho. Moisissures des grains du sorgho. Rapport d'activités 1383. Doc N: 38/84 multigraphie, p. 32, CNRA Bambey, Senegal, Bambey, Senegal, 1984.

[12] R. Bandyopadhyay, D. R. Butler, A. Chandrashekar, R. Kanaka, and S. S. Navi, "Biology, epidemiology, and management of sorghum grain mold," in Technical and Institutional Options for Sorghum Grain Mold Management, A. Chandrashekar, R. Bandyopadhyay, and A. J. Hall, Eds., pp. 34-51, ICRISAT, Patancheru, India, 2000.

[13] R. P. Thakur, B. V. S. Reddy, S. Indira et al., Sorghum Grain Mold. Information Bulletin No. 72. International Crops Research Institute for the Semi-Arid Tropics, ICRISAT, Patancheru 502324, Andhra Pradesh, India, 2006.
[14] J. C. Denis and J. C. Girard, "Factors affecting the development of sorghum grain molds in Senegal," in Sorghum Diseases, a World Review, R. J. Williams, R. A. Frederiksen, L. K. Mughogho, and G. D. Bengston, Eds., pp. 144-153, ICRISAT, Patancheru, Andhra Pradesh, India, 1980.

[15] K. A. Seifert, T. Aoki, R. P. Baayen et al., "The name Fusarium moniliforme should no longer be used," Mycological Research, vol. 107, no. 6, pp. 643-644, 2003.

[16] S. Audilakshmi, I. K. Das, R. B. Ghorade et al., "Genetic improvement of sorghum for grain mould resistance: I. Performance of sorghum recombinant inbred lines for grain mould reactions across environments," Crop Protection, vol. 30, no. 7, pp. 753-758, 2011.

[17] R. Thakur, B. Reddy, and K. Mathur, Screening Techniques for Sorghum Diseases. Information Bulletin, International Crops Research Institute for, Patancheru, Andhra Pradesh, India, 2007.

[18] S. D. Singh and R. Bandyopadhyay, "Grain mold," in Compendium of Sorghum Diseases, R. A. Frederiksen and G. N. Odvody, Eds., pp. 38-40, The American Phytopathological Society, St. Paul, MN, USA, Second Edi edition, 2000.

[19] V. A. Tonapi, R. R. Mundada, S. S. Navi et al., "Effect of temperature and humidity regimes on grain mold sporulation and seed quality in sorghum (Sorghum bicolor(L.) Moench)," Archives Of Phytopathology And Plant Protection, vol. 40, no. 2, pp. 113-127, 2007.

[20] S. Audilakshmi, J. W. Stenhouse, and T. P. Reddy, "Genetic analysis of grain mold resistance in white seed sorghum genotypes," Euphytica, vol. 145, no. 1-2, pp. 95-101, 2005.

[21] R. Rodríguez-Herrera, W. L. Rooney, D. T. Rosenow, C. N. Aguilar-González, and A. R. Quero-Carrillo, "Genetic control and heritability of resistance to grain mold in F2:5 sorghum families with non-pigmented testa," Plant Breeding and Seed Science, vol. 55, pp. 34-43, 2007.

[22] S. M. M. Mortazavian, H. R. Nikkhah, F. A. Hassani, M. Sharif-al-Hosseini, M. Taheri, and M. Mahlooji, "GGE biplot and AMMI analysis of yield performance of barley genotypes across different environments," Journal of Agricultural Science and Technology, vol. 16, pp. 609-622, 2014.

[23] M. Ding, B. Tier, and W. Yan, "Application of GGE biplot analysis to evaluate Genotype (G), Environment (E) and $\mathrm{G} \times \mathrm{E}$ interaction on P. radiata: a case study," in Proceedings of the Australasian Forest Genetics Conference Breeding for Wood Quality, Hobart, Tasmania, April 2007.

[24] K. R. Gabriel, "The biplot graphic display of matrices with application to principal component analysis," Biometrika, vol. 58, no. 3, pp. 453-467, 1971.

[25] W. Yan, L. A. Hunt, Q. Sheng, and Z. Szlavnics, "Cultivar evaluation and mega-environment investigation based on the GGE biplot," Crop Science, vol. 40, no. 3, pp. 597-605, 2000.

[26] L. S. Fayeun, G. C. Alake, and A. O. Akinlolu, "GGE biplot analysis of fluted pumpkin (Telfairia occidentalis) landraces evaluated for marketable leaf yield in Southwest Nigeria," Journal of the Saudi Society of Agricultural Sciences, vol. 17, no. 4, pp. 416-423, 2018.

[27] P.-P. Zhang, H. Song, X.-W. Ke et al., "GGE biplot analysis of yield stability and test location representativeness in proso millet (Panicum miliaceum L.) genotypes," Journal of Integrative Agriculture, vol. 15, no. 6, pp. 1218-1227, 2016.

[28] W. Yan, "GGEbiplot-A windows application for graphical analysis of multienvironment trial data and other types of two-way data," Agronomy Journal, vol. 93, no. 5, pp. 1111-1118, 2001. 
[29] F. E. Torres, F. D. Tardin, P. E. Teodoro et al., "Identification of sorghum hybrids with high phenotypic stability using GGE biplot methodology," Genetics and Molecular Research, vol. 15 , pp. 1-8, 2016

[30] I. Makanda, J. Derera, P. Tongoona, and J. Sibiya, "Genetic and GGE biplot analyses of sorghum germplasm for stem sugar traits in Southern Africa," African Journal of Agricultural Research, vol. 7, pp. 212-223, 2012.

[31] R. M. Phuke, K. Anuradha, K. Radhika et al., "Genetic variability, genotype $\times$ environment interaction, correlation, and GGE biplot analysis for grain iron and zinc concentration and other agronomic traits in RIL population of sorghum (sorghum bicolor L. Moench)," Frontiers in Plant Science, vol. 8, pp. 1-13, 2017.

[32] O. Kempthorne, An Introduction of Genetic Statistics, John Willey \& Sons Inc, New York, NY, USA, 1957.

[33] B. Sarr, S. Ndjendole, O. Diouf, M. Diouf, and H. RoyMacauley, "Suivi de l'état hydrique du sol et de la température du couvert de maïs au Sénégal," Sécheresse.vol. 10, pp. 129$135,1999$.

[34] R. P. Thakur, B. V. S. Reddy, and K. Mathur, Screening Techniques for Sorghum Diseases. Information: Bulletin No. 76, International Crops Research Institute for the Semi-Arid Tropics, Patancheruvu, India, 2007.

[35] E. Frutos, M. P. Galindo, and V. Leiva, “An interactive biplot implementation in $\mathrm{R}$ for modeling genotype-by-environment interaction," Stochastic Environmental Research and Risk Assessment, vol. 28, no. 7, pp. 1629-1641, 2014.

[36] Foundation for Statistical Computing, A Language and Environment for Statistical Computing, $\mathrm{R}$ Foundation for Statistical Computing, Vienna, Austria, 2019.

[37] W. Yan and N. A. Tinker, "Biplot analysis of multi-environment trial data: principles and applications," Canadian Journal of Plant Science, vol. 86, no. 3, pp. 623-645, 2006.

[38] W. Yan and M. S. Kang, GGE Biplot Analysis: A Graphical Tool for Breeders, Geneticists, and Agronomists, CRC Press, Boca Raton, FL, USA, 1st edition288 pages, CRC Press, Boca Raton, FL, USA, 2003.

[39] E. Gasura, P. S. Setimela, and C. M. Souta, "Evaluation of the performance of sorghum genotypes using GGE biplot," $\mathrm{Ca}$ nadian Journal of Plant Science, vol. 95, no. 6, pp. 1205-1214, 2015.

[40] M. Mare, P. Manjeru, B. Ncube, and G. Sisito, "GGE biplot analysis of genotypes by environment interaction on Sorghum bicolor L. (Moench) in Zimbabwe," African Journal of Plant Science, vol. 11, no. 7, pp. 308-319, 2017.

[41] A. Ratnadass, P. S. Marley, M. A. Hamada et al., "Sorghum head-bugs and grain molds in West and Central Africa: I. Host plant resistance and bug-mold interactions on sorghum grains," Crop Protection, vol. 22, no. 6, pp. 837-851, 2003.

[42] L. K. Prom, N. Cissé, R. Perumal, and H. Cuevas, "Screening of sorghum lines against long smut and grain mold pathogens," International Journal of Plant Pathology, vol. 8, no. 2, pp. 23-27, 2017.

[43] L. K. Prom, R. Perumal, N. Cissé, and C. R. Little, "Evaluation of selected sorghum lines and hybrids for resistance to grain mold and long smut fungi in Senegal, West Africa," Plant Heal Prog, vol. 15, pp. 28-31, 2014.

[44] C. Diatta, Development of sorghum [sorghum bicolor (L.) moench] for resistance to grain mold in senegal, $\mathrm{PhD}$ Thesis, University of Ghana, Accra, Ghana, 2016.

[45] R. R. Klein, R. Rodriguez-Herrera, J. A. Schlueter, P. E. Klein, Z. H. Yu, and W. L. Rooney, "Identification of genomic regions that affect grain-mould incidence and other traits of agronomic importance in sorghum," Theoretical and Applied Genetics, vol. 102, no. 3, pp. 307-319, 2001.

[46] Intsormil, "Dual purpose grain and forage sorghum for Central America," INTSORMIL Impacts Bull, vol. 37, 2008.

[47] R. Kenga, S. O. Alabi, and S. C. Gupta, "Combining ability studies in tropical sorghum (Sorghum bicolor (L.) Moench)," Field Crops Research, vol. 88, no. 3, pp. 251-260, 2004.

[48] A. Toure, F. R. Miller, and D. T. Rosenow, "Heterosis and combining ability for grain yield and yield components in Guinea sorghums," African Crop Science Journal, vol. 4, pp. 383-391, 1996.

[49] W. Yan and I. Rajcan, "Biplot analysis of test sites and trait relations of soybean in Ontario," Crop Science, vol. 42, no. 1, pp. 11-20, 2002. 